\title{
Inclusive Education at a South African University: Awakening the Sensitivities and Democratic Consciousness of Pre-Service Teachers
}

\author{
Cina P. Mosito \\ Toyin Mary Adewumi \\ Charlene Nissen \\ Intermediate Phase Department, \\ Faculty of Education, \\ Cape Peninsula University of Technology, \\ South Africa
}

DOI: https://doi.org/10.36941/ajis-2020-0094

\begin{abstract}
One of the chief goals of inclusive education is to provide pre-service teachers with a learning environment and prospects that enable them to become independent, responsible and critical educators. This study sought to determine how pre-service teachers at a South African university experienced inclusive education training. A purposeful sample of 6 pre-service teachers was selected. Data were collected using open-ended questionnaires which were exploratory in nature, and then analysed thematically. Findings showed inter alia that studying inclusive education proved to be an "eye opener": students were enlightened to various aspects of being an educator: (i) curriculum differentiation, (ii) diversity, (iii) learners' rights and (iv) the fact that learners experiencing various barriers to learning can be accommodated successfully in regular classrooms. It was revealed that studying inclusive education allowed pre-service teachers to appreciate the scope, value and higher purpose of teaching. The study shows that awareness of inclusive education enriches the training of pre-service teachers in South African schools.
\end{abstract}

Keywords: diversity, pre-service training, inclusive education, learner, South Africa

\section{Introduction}

The importance of preparing teachers adequately for mainstream teaching cannot be overemphasised. Teachers need to be trained to teach increasingly diverse learners in one inclusive classroom space (Kumar, 2014). The main challenge encountered by post-liberation South Africa is achieving the constitutional values of equality and civil rights. Fundamental is the right to equality in basic education for every learner, as well as for those who experience barriers to learning. Before liberation, children were taught in separate schools on the basis of racial demographics and disabilities or impairment (Spaull, 2015).

To align education in the country with universal principles of inclusion, policy which establishes an inclusive education system was legislated in South Africa (Mitchell \& Sutherland, 2020). The South African government's guarantee of inclusive education is defined in the 1996 Constitution, including other policies, such as the South African Schools Act (SASA) of 1996 and the White Paper number 6 
of 2001: Building an Inclusive Education and Training System (Department of Education, 2001).

The white paper sets out the principles of inclusion for all learners. These principles state that all learners can learn with support. It acknowledges and respects learner diversity in the form of ethnicity, language, class, gender, disability or HIV status. It encourages education structures, systems and learning methodologies to accommodate all learner needs. The white paper states that attitudes, behaviour, teaching methodologies, curricula and environment must change to accommodate all learners' needs. It further states that learners must be allowed to participate in the learning process. White Paper 6 advocates increased participation which reduces barriers to learning (Department of Education, 2001; Donohue \& Bornman, 2014).

To articulate how the vision of Education White Paper 6 can be realised in schools, a document known as Screening, Identification, Assessment and Support (SIAS), was introduced in 2008 (Department of Education, 2008). SIAS sets out guidelines on how teachers can identify learners and what causes barriers to learning. Teachers are required to assess and support learners in accordance with the type and severity of the barrier. For example, learners should be assisted through the individual support plan (ISP). Each learner may be referred to an institutional level support team (ILST) in a school organized by a teacher who had attended SIAS workshop should the ISP fail. The ISP offered to the learner will be reviewed to ascertain the adequacy of the support. The districtbased support team (DBST) will be informed about the learner. SIAS will be completed by DBST with biographical information and a scholastic report of the learner (Department of Education, 2008).

Inclusive education is entrenched in South African policy in anticipation that teacher education will prepare pre-service teachers to teach inclusively. Inclusive education modules are taught in South African higher institutions (Republic of South African, 2015). Inclusive education seeks to address and respond to, the diversity of learner needs by means of greater involvement in schooling, cultural practices and community activities; to reduce marginalisation within schooling (Peters, 2004; UNESCO, 2009). A national project on inclusive education known as 'Teaching For All' initiated a curriculum on inclusive education for initial teacher education (ITE) which was introduced in all South African institutions. The aim of the Teaching For All project is to inculcate in pre-service teachers in South Africa, skills, knowledge and a constructive attitude for teaching inclusively in diverse classrooms. Inclusive education develops an education system that understands the education rights of every child: "Every learner matters and matters equally"(UNESCO, 2017; 13). The module adopts a broad social justice and human-rights-based approach and recognises pre-service teachers as agents of change who can develop an equitable and inclusive education system by becoming inclusive teachers.

There are structures and measures to equip and train teachers in inclusion of all learners in the regular classrooms. Teachers still encounter challenges, however, such as inadequate training, inappropriate skills, over-crowding, inadequate resources, lack of support and monitoring, behavioural problems and lack of teachers (Yada \& Savolainen, 2017; Human Rights Watch, 2017; Taylor, 2017; Adewumi \& Mosito, 2019; Dreyer, 2015). It is not entirely clear how well teachers are prepared and equipped for the inclusion of diverse learners in the regular classrooms. This study sought to investigate the experiences of pre-service teachers studying inclusive education at a university in South Africa.

\subsection{Objectives}

This study sought to explore the experiences of pre-service teachers studying inclusive education within the South African education context. It investigates aspects of inclusive education that inform planning for a particular subject. 


\section{Materials and Methods}

\subsection{Research Approach and Design}

A qualitative research approach was used to explore and better understand issues from experiences learned, or perspectives of, participants (Creswell \& Creswell, 2017). A qualitative approach allowed researchers to be flexible in probing participants' experiences of studying inclusive education. The researchers utilised a case study qualitative research design. Lichtman (2014) defines research design as an arrangement or methodology that the researcher employs to actualize his or her study. Creswell and Creswell (2018) argue that a research design is a plan and procedures emanating from broad assumptions, which becomes a more detailed method of data collection and analysis. Case study research is an effective methodology for investigating and understanding issues that are elusive in actual settings; such as in exploring the experiences of student teachers studying inclusive education (Stewart, 2012).

\subsection{Population, Sample and Sampling Techniques}

In this study, one university of the four in the Western Cape was the sample under study. A sample is a subgroup of the population you are interested in (Kumar, 2019). Emmel (2013) identifies two different types of sampling: probability and non-probability sampling. He points out that in nonprobability sampling, the sampling group members are selected in a non-random manner and not everyone in the population participates. For the purpose of this study, a purposive sampling method was deployed. Samples comprised 6 pre-service teachers (PGCE-FET) who volunteered to participate in the study at one university in South Africa. For all of the six students, inclusive education was a compulsory subject in their course. Through the utilization of a purposive sampling method, the researchers gained more knowledge about the experiences of studying inclusive education. The researchers selected participants and a suitable site for this research where they could form an understanding of the experiences of studying inclusive education on their teaching.

\subsection{Data Collection Instruments}

The instruments of data collection for this study were open-ended questionnaires. An open-ended questionnaire is a qualitative research technique that involves conducting intensive research with a small number of participants to investigate their views on the subject under study (Dudovskiy, 2016). Through the use of the open-ended questionnaires, the researchers obtained a greater insight into the experiences of studying inclusive education on pre-service teachers' teaching within the South African education context.

\subsection{Data Analysis}

Data collected were thoroughly coded according to the themes. The themes were analysed to address the main objective which was to investigate the experiences of studying inclusive education. Data from the open-ended questionnaires were coded to form data sets. Responses were transcribed and interpreted, based on objectives. Data were structured and compiled data sets for each objective. Researchers developed inductive themes for the study.

Credibility means that which can be trusted, based on rigorous evidence or argument, and authority. Credibility is a vital factor that grants authority to the view of the participants. Credibility minimises the risk of bias. It makes the finding of the study reliable (Pacho, 2015; Brantlinger, 2005). Some of the methods for ensuring credibility of any research are data triangulation, member checking and investigator triangulation (Salmona, Lieber, Kaczynski, 2019). This study employed investigator triangulation. Three researchers were involved in the data collection process, to ensure that in-depth, rich and truthful data were gathered. 


\subsection{Ethical procedures}

Ethical procedures were observed before, during and after the study. Ethical clearance for the study was granted by the ethics committee of the faculty. All PGCE-FET students were invited and six voluntarily participated in the study. They signed informed consent to show that they were not coerced into participating in this study. Participants were treated anonymously and assured of confidentiality. Participant names were changed to pseudonyms: ST1-ST6 (student teacher). Researchers committed to using data for research purposes only; not as a form of academic assessment.

\section{Results}

\subsection{The influence of Inclusive Education on how pre-service teachers think about teaching}

One of the current educational 'hot' topics is inclusive education. There are many views on the subject. Inclusive education assists teachers and learners to appreciate diversity in communities. Inclusive education helps teachers and learners to appreciate the values of respect, diversity, human rights, curriculum differentiation and loving each other. A plethora of responses were captured in response to the question of how studying Inclusive Education has influenced how they think about teaching. Being an inclusive education student has improved the consciousness/understanding of pre-service teacher of the implementation of the inclusion policy.

ST1 said:

It enhanced awareness of inclusive education factors, broader perspective of what it entails and how to implement it in the classroom.

ST2 believed that all learners should be accommodated in regular classrooms with adequate support.

Teaching does include a lot of aspects contributing to the effectiveness of education. All case regarding learners are not necessary about special schools, most learners just need to be included rather than send straight to special schools. All to stay away from saying a learner has a problem. What we should ask ourselves is what is the problem (not a child has a problem). (ST2)

According to $\mathrm{ST}_{3}$, being an inclusive education student was an eye-opener and has improved her passion for teaching.

Inclusive education made me to love teaching more and ready to go and teach it made me to be aware of so many aspects including diversity, rights and curriculum differentiation (ST3).

In corroboration with $\mathrm{ST}_{3}, \mathrm{ST}_{4}$ confirmed his desire to teach and to adopt learner-centred teaching methods for inclusion of all learners.

Being in inclusive education gave me an influence to be a teacher. I am now eager to be in the teaching industry. Inclusive education influenced me in making professional relationship with the teacher colleagues. Some units made me to be able to choose topics that will be more learner-centered (ST4)

Realising that not all educators include all learners resolved $\mathrm{ST}_{5}$ to be an inclusive educator when the time was right.

It made me realise that not all educators do implement the inclusive education in classroom. Then it helped me to realise that gap. Then I took a decision that when I am a qualified educator, I will implement inclusive education. It helps all learners to achieve the learning productivity (ST5). 
On his part, ST6 revealed that he has learnt proper lesson preparation and planning from being an inclusive education student. This pre-service teacher revealed that he now knows which is the right door to knock at for assistance.

Teaching is not for everyone. Discipline, focus and consistency is mandatory. As an inclusive education teacher, the proper planning, preparation and monitoring of the lessons. The module has prepared me to participate and complete in the profession and know the correct avenues to seek help if necessary (ST6).

This study established that participating in inclusive education modules enriched the teaching of participating pre-service teachers.

\subsection{Aspects of inclusive education that inform planning for a particular subject}

An appropriate basis in inclusive education may be established and sustained in the classroom through practices that offer teachers an opportunity to plan and deliver lessons that meet the needs of all learners and result in positive learning outcomes. Participating pre-service teachers were asked to relate aspects of inclusive education that inform their planning for a particular subject. From the responses, participants gained an appreciation for inclusive education that informed their planning for a particular subject. Pre-service teachers' responses are captured below.

ST1 explained that he/she was optimistic and the same time had room for dissatisfactions from his learners.

When planning lesson, I have to exhibit high expectations for my learners. I always have time for disappointments. Make sure to make extra time for learners who could not grab the contents from a class. I sometimes let learners to relate to certain situations in order for them to own the lesson.

ST 2 utilised the CAPS document, curriculum differentiation, respect for learners' rights and consulted different sources as a result of learner diversity in the classroom.

I consult the CAPS document. The diversity of learners (socio-economic status, gender, race, etc. for relevance. Have different implementation of curriculum difference. Consider not to conflict with learners rights. Enquire information from different sources about the topic.

ST 3 employed different assessment tasks to determine how well learners are learning which is important to improving teaching and learning.

Method of addressing lesson pedagogy. Assessment to check the capability of my learners either formal or informal kind of assessment as the feedback to my lesson.

Understanding learner diversity and different learning needs informed his planning. According to ST 4 , the need to accommodate all learners in teaching/learning, different assessment tasks and constructive criticisms are key in planning.

ST 4: Curriculum differentiation-learners do not learn in the same way, need to be aware of the different ways learning occurs -Use teaching media-video, audio to cater for all learners and ensure that each one is learning actively. -Assessment and feedback. Allow learners to show/ demonstrate their understanding in various ways. Do not use one form of assessment only and always give positive feedback to uplift children's confidence.

According to ST 5 , planning is determined by the lesson or subject and should accommodate all the learners. This student teacher emphasised that teaching/learning should start from known to unknown, as learners come to school with some form of knowledge, they are not "empty vessels".

ST 5 noted: 
It depends on the lesson or the subjects. As an inclusive educator, you must always know that the lesson is not about you. It is about the learners. So you must plan it to accommodate all of them. You need to let them own the lesson. As an educator, you need to guide them. Let them experience everything. You must always have the aspect in your mind that they know. All you need is to help them experience it.

In his response, ST6 revealed that planning should be informed by diversity, and access to education.

ST 6 explained:

Accommodativeness, easy access, it should be effective and influential, relevant content, diversity. Those are some but a few aspects that are promoted and encouraged by the inclusive education. Planning also provides alteration and correction of information to suit learners need.

In this section, the participants understanding of aspects of inclusive education that informs planning for a particular subject is clearly aligned to principles of the Teaching For All curriculum that informed their tuition.

\section{Discussion}

This study explored how pre-service teachers experienced inclusive education training at a university in South Africa. The study revealed that studying inclusive education enlightened participants' teaching. One of the findings showed that participants gained new information and insight into what is required to include all learners in the classroom. Page et al., (2019) state that teacher education in the area of barriers to learning is essential. Bouillet (2013) stresses that inclusive education requires well-trained teachers and a high standard of service. High quality service and training assist teachers to effectively implement inclusive education. According to Wiaxowski (2012) inclusive education in a South African context, has been organized in the form of White Papers that emphasise the need for well-qualified and prepared teachers. The Education White Paper 6 highlights a need for well-qualified, professional teachers who are prepared to disseminate inclusive education within a classroom setting. Page et al. (2019) cite Bingham et al. (2010) who share the same view that teacher aides who are well trained and supervised, contribute to the success of learners in inclusive education settings.

This study established that some of the participants came to regard inclusive education as an "eye opener". They suddenly realised that learners experiencing various barriers to learning can be integrated successfully into regular classrooms. Wilson (2017) stresses that classrooms, pedagogy, and curricular materials should be improved to accommodate all learners. It was revealed that being inclusive education students enabled participants to appreciate inclusive education, diversity, rights and curriculum differentiation. The aim of differentiation is to make content, process and learning environments accessible to all learners to succeed. Differentiating involves using many teaching strategies that encourage inclusion of all learners (Roy, Guay \& Valois, 2013).

Other findings from this study show that pre-service teachers: (i) learnt to apply learnercentred approaches in their teaching, (ii) gained excitement to teach, (iii) developed professional relations with colleagues, and (iv) made decisions to be inclusive teachers themselves in order to accommodate all learners. The study established that being inclusive education students allowed participants to be more disciplined, focused, consistent, value adequate planning and seek assistance when necessary. Regular classroom teachers should use appropriate teaching programmes, adapt present curriculum materials, evaluate learner progress and consult special education needs teachers to accommodate learners with barriers to learning (Babino et al., 2019).

It was discovered in this study that some aspects of inclusive education inform participant planning. These aspects include learner diversity, learner rights, and capability of learners. The study established that accommodating all learners through curriculum differentiation improved their planning. Possi and Milinga (2018) are of the view that curriculum differentiation strategies may involve: 
- playing videos, singing, providing audiobooks, asking students to act out a scene, incorporating charts and illustrations within texts,

- giving both spoken and written directions to tasks

- using relevant physical objects, such as money when teaching Mathematics skills, allotting time for students to create artistic reflections and interpretations of lessons.

This finding showed that these tactics help learners grasp core concepts of lessons and make class more engaging, (Possi \& Milinga, 2018).

Teaching in line with learners' diversity involves transforming classrooms to cater for all learners from various ethnic groups and linguistic minorities, rural populations, those affected by HIV and AIDS, and those who have exceptional learning needs (Possi \& Milinga, 2018). According to Siegle et al., (2016), inclusive education is described as a process of addressing the diverse needs of all learners by reducing barriers to learning, within the learning environment. UNESCO(1994) states that "Inclusion is a process of addressing and responding to the diversity of needs of all learners through increasing participation in learning, cultures and communities and reducing exclusion within and from education and further more maintains that it is the removal of all barriers to learning".

\section{Conclusion}

The objective of the study was to explore, compare and analyse the experiences of pre-service teachers studying inclusive education: to investigate aspects of inclusive education that inform their planning for a particular subject at a particular university in South Africa. Some significant findings from the study include how pre-service teachers' became aware of a broader view of inclusive education, and education. Studying inclusive education enlightened them. Participants learnt that inclusion of all learners should be accompanied by suitable support for learners. Participants gained a greater passion for teaching, understanding proper lesson preparation and planning with the use of learner-centred strategies. This study revealed that some aspects of the inclusive education module informed participant planning for their various subjects. Aspects such as curriculum differentiation, respect for learners' rights, learner diversity, different assessment strategies and inclusion of all learners enriched their understanding of what it is to be an educator in a post-liberation South Africa, sensitive to the needs of others and equipped to be agents for democratic change.

\section{Limitations and Recommendations}

The participating pre-service teachers seemed to 'tick all the right boxes' and speak a language of inclusion as taught in their course. It remains to be seen how the knowledge gets translated into practice. A follow up study could then be designed to explore and interrogate in classroom practices and experiences of newly graduated teachers who have been exposed to inclusive education in their initial teacher education.

\section{Acknowledgement}

This work was supported by the European Union "Teaching for All" grant administered by British Council South Africa.

\section{References}

Adewumi, T. M., \& Mosito, C. (2019). Experiences of teachers in implementing inclusion of learners with special education needs in selected Fort Beaufort District primary schools, South Africa. Cogent Education, 6(1), 1703446.

Babino, A., Araujo, J. J., \& Maxwell, M. L. (2019). Critical, Compelling, and Linguistically Scaffolded Literature. Texas Journal of Literacy Education, 7(1), 44-64. 
Bingham, G. E., Hall-Kenyon, K. M., \& Culatta, B. (2010). Systematic and engaging early literacy: Examining the effects of paraeducator implemented early literacy instruction. Communication Disorders Quarterly, 32(1), 38-49.

Bouillet, D. (2013). Some aspects of collaboration in inclusive education-teachers' experiences. Center for Educational Policy Studies Journal, 3(2), 93-117.

Brantlinger, E., Jimenez, R., Klingner, J., Pugach, M., \& Richardson, V. (2005). Qualitative studies in special education. Exceptional children, 71(2), 195-207.

Creswell, J. W., \& Creswell, J. D. (2017). Research design: Qualitative, quantitative, and mixed methods approaches. Sage publications.

Donohue, D., \& Bornman, J. (2014). The challenges of realising inclusive education in South Africa. South African Journal of Education, 34(2).

Dreyer, L. M. (2015). Experiences of parents with children diagnosed with reading difficulties. Southern African Review of Education with Education with Production, 21(1), 94-111.

Dudovskiy, J. (2016). Purposive sampling. Research Methodology.

Emmel, N. (2013). Sampling and choosing cases in qualitative research: A realist approach. Sage.

Human Rights Watch (2017). Human Rights Watch Submission to the Periodic Review of South Africa.

Kumar, S. (2014). Inclusive classroom and social diversity in India: Myths and challenges. Journal of Indian Research, 2(1), 126-140.

Kumar, R. (2019). Research methodology: A step-by-step guide for beginners. Sage Publications Limited.

Lawrence, M. (2012). The issues and challenges that foundation phase educators experience when teaching learners with Attention Deficit Hyperactivity Disorder (ADHD) (Doctoral dissertation).

Lichtman, M. (2014). Drawing meaning from the data. Qualitative research for the social.

Mitchell, D., \& Sutherland, D. (2020). What really works in special and inclusive education: Using evidence-based teaching strategies. Routledge. London

Pacho, T. (2015). Exploring participants' experiences using case study. International Journal of Humanities and Social Science, 5(4), 44-53.

Page, A., Boyle, C., McKay, K., \& Mavropoulou, S. (2019). Teacher perceptions of inclusive education in the Cook Islands. Asia-Pacific Journal of Teacher Education, 47(1), 81-94.

Peters, S. J. (2004). Inclusive Education: An EFA Strategy For All Children 31195. World Bank Education Advisory Service.

Possi, M. K., \& Milinga, J. R. (2018). Learner diversity in inclusive classrooms: The interplay of language of instruction, gender and disability. MOJES: Malaysian Online Journal of Educational Sciences, 5(3), 28-45.

Republic of South African Legislature (2015). Revised Policy on the Minimum Requirements for teacher Education Qualifications.

Roy, A., Guay, F., \& Valois, P. (2013). Teaching to address diverse learning needs:Development and validation of a differentiated instruction scale. International Journal of Inclusive Education, 17(11), 1186-1204.

Salmona, M., Lieber, E., \& Kaczynski, D. (2019). Qualitative and Mixed Methods Data Analysis Using Dedoose: A Practical Approach for Research Across the Social Sciences. SAGE Publications, Incorporated.

Siegle, D., Gubbins, E. J., O’Rourke, P., Langley, S. D., Mun, R. U., Luria, S. R., ... \& Plucker, J. A. (2016). Barriers to underserved students' participation in gifted programs and possible solutions. Journal for the Education of the Gifted, 39(2), 103-131.

South Africa Department of Education (2001). Education white paper 6: Special needs education: building an inclusive education and training system. Department of Education: Pretoria.

South Africa. Department of Education (2008). National strategy on screening, identification, assessment and support: School pack. Department of Education: Pretoria.

Spaull, N. (2015). Schooling in South Africa: How low-quality education becomes a poverty trap. South African Child Gauge, 12, 34-41.

Stewart, J. (2012). Multiple-case study methods in governance-related research. Public Management Review, 14(1), $67-82$.

Taylor, J. (2017). Teacher demotivation in a national eikaiwa chain in Japan. Transformation in language education. Tokyo: JALT.

UNESCO (2009). Inclusive education: The way of the future. Final Report of the International Conference of Educ (48th Session). Paris: UNESCO

UNESCO (2017). Global Education Monitoring Report: Accountability in Education - Meeting Our Commitments. Paris: UNESC

Wiazowski, J. (2012). On the Dirt Road to Inclusion. International Journal of Special Education, 27(2), $148-156$.

Wilson, J. D. (2017). Reimagining disability and inclusive education through universal design for learning. Disability Studies Quarterly, 37(2). 